$41(3) \mid 2012$

Recomposiciones territoriales de las periferias de las metrópolis andinas

\title{
Producir y habitar la periferia. Los nuevos conjuntos de vivienda de bajo costo en México (ZMVM)
}

Produire et habiter la périphérie. Les lotissements récents de logements de bas coût à Mexico (ZMVM)

Making and living the edge. New low-income housing estates in the Valley of Mexico metropolitan area (ZMVM)

Céline Jacquin

\section{(2) OpenEdition}

Journals

Edición electrónica

URL: http://journals.openedition.org/bifea/186

DOI: 10.4000/bifea.186

ISSN: 2076-5827

Editor

Institut Français d'Études Andines

Edición impresa

Fecha de publicación: 31 diciembre 2012

Paginación: 389-415

ISSN: 0303-7495

Referencia electrónica

Céline Jacquin, «Producir y habitar la periferia. Los nuevos conjuntos de vivienda de bajo costo en México (ZMVM) », Bulletin de l'Institut français d'études andines [En línea], 41 (3) | 2012, Publicado el 01 agosto 2013, consultado el 06 noviembre 2020. URL : http://journals.openedition.org/bifea/186 ; DOI : https://doi.org/10.4000/bifea.186

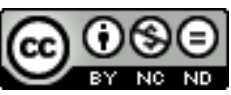

Les contenus du Bulletin de l'Institut français d'études andines sont mis à disposition selon les termes de la licence Creative Commons Attribution - Pas d'Utilisation Commerciale - Pas de Modification 4.0 International. 


\title{
Producir y habitar la periferia Los nuevos conjuntos de vivienda de bajo costo en México (ZMVM)
}

\author{
Céline Jacquin*
}

\begin{abstract}
Resumen
El presente artículo propone analizar la experiencia de la metrópoli de los habitantes de los megaconjuntos de vivienda de bajo costo en las partes más alejadas de la periferia del Valle de México. Adoptamos una mirada transversal con inflexión en la etapa de la accesión a la propiedad. Observando las prácticas urbanas de las familias tanto a escala metropolitana como local, desde este punto de crisis, se destaca la emergencia de colectividades, donde sobresale el papel de la mujer. El conjunto de observaciones permite cuestionar desde el interior la política nacional de vivienda y un modo de producir la ciudad impulsado desde quince años.
\end{abstract}

Palabras clave: Vivienda de interés social, periferia, Zona Metropolitana del Valle de México, movilidad residencial, mujeres

\section{Produire et habiter la périphérie. Les lotissements récents de logements de bas coût à Mexico (ZMVM)}

\section{Résumé}

Nous nous intéressons dans cet article à l'expérience urbaine de groupes sociaux résidents des lotissements d'intérêt social produits ces quinze dernières années dans les parties les plus reculées de la zone métropolitaine de Mexico. En posant un regard longitudinal sur une étape charnière pour une génération qui accède à la propriété, on observe d'importantes évolutions dans les pratiques urbaines des familles, à l'échelle locale et métropolitaine, ainsi que l'émergence de communautés et du renforcement du rôle des femmes en tant qu'acteur central de celles-ci. Ces mécanismes soulignent les limites propres à l'actuel mode de production du logement et de la ville.

* Candidata a doctora en Estudios urbanos por la Universidad Paris-Est, Lab'Urba (Francia). Investigadora asociada al Centro francés de Estudios Mexicanos y Centroamericanos (CEMCA): Sierra Leona 330, Lomas de Chapultepec, delegación Miguel Hidalgo CP 11000, México, D.F. Email: celija@gmail.com 
Mots clés : Habitat d'intérêt social, périphérie populaire, Zone Métropolitaine de Mexico, mobilité résidentielle, espace public, femmes

\title{
Making and living the edge. New low-income housing estates in the Valley of Mexico metropolitan area (ZMVM)
}

\begin{abstract}
This paper examines the urban experience lived by the inhabitants of new social housing developments located in the most remote parts of Mexico City's metropolitan periphery. Along the family trajectories of popular urban group, one generation accesses property. This moment constitues a turning-point: from that specific moment, the family developp urban practices at local and metropolitan scale. Two of the most significant phenomena generated are the emergence of communities and the relative empowerment of women as a central actor. Through the qualitative analysis of these processes, the defaults of the national housing policy are enlighten.
\end{abstract}

Keywords: Social Housing, working-class suburb, Valley of Mexico Metropolitan Area, residential mobility, women

El presente artículo se interesa en las dimensiones territoriales inducidas por la producción reciente de vivienda de interés social en la periferia lejana de la ciudad de México. Este modo de hábitat, al permitir el acceso a la propiedad a grupos sociales carentes de patrimonio, atrae una parte consistente de la población metropolitana y tiende a crecer con constancia. La cuestión de la vivienda «terminada» de bajo costo, no solo ayuda a revelar los grandes problemas de planeación urbana sino que constituye además un enfoque para entender las estrategias de los grupos populares acerca de la vivienda y de la reproducción entre generaciones. El acceso a la propiedad refiere a un periodo clave en la trayectoria de los hogares, que coincide con la etapa de la independización de las parejas. La instalación de poblaciones numerosas, homogéneas en forma casi simultánea en espacios residenciales aislados de la urbe, considerando a una clase social que no tiene poder de elección sobre su localización residencial, desequilibra las redes socio-familiares y plantea nuevas condiciones de convivencia para los hogares. En suma, esta situación específica permite evidenciar ciertos fenómenos alrededor del habitar y de la producción social del espacio urbano por los grupos populares. El factor con el mayor impacto en los modos de vida es el alejamiento de los hogares con sus espacios de vida anteriores, los cuales son fuertemente vinculados con las redes familiares. El instalarse en los nuevos espacios residenciales de bajo costo representa una ruptura en su trayectoria. Se suman a la experiencia fuertes dificultades económicas concomitantes a la instalación en una vivienda nueva y en una zona de reciente urbanización donde faltan o fallan los servicios en un principio, lo que genera tensión en la red familiar. En el hogar así como en la colectividad, las nuevas condiciones impactan las definiciones de los roles y hacen de la mujer la protagonista principal. 
El objeto del presente texto es entonces ilustrar un conjunto de procesos por los cuales se domestica un espacio poco funcional, desde su diseño hasta su relación con la ciudad. Desde este punto los esfuerzos de los «pioneros» se concentran en parte en la creación de redes de solidaridad sustitutas en el ámbito local. Analizamos aquí estos mecanismos tales como «habilidades», por medio de las cuales los habitantes se apropian del nuevo espacio residencial y se organizan frente a las lagunas de este espacio de vida — como lo han planteado varios trabajos en la linea de M. de Certeau (1996), Berry-Chikhaoui \& Deboulet (2000)_, pero también producen una nueva relación con su entorno y con la metrópoli.

\section{LA VIVIENDA DE INTERÉS SOCIAL RECIENTE EN MÉXICO}

Las condiciones económicas y políticas nacionales a final de los años 1990 han planteado nuevas reglas de acceso a la vivienda, financiamiento público y nuevas condiciones de producción de la vivienda de interés social. Esta categoría de vivienda de bajo costo es Ilamada vivienda «económica» o de «interés social»1.

Al final del siglo veinte, las crisis económicas han agotado el margen de acción del Estado mexicano en materia de política social. Los fondos públicos de vivienda para los trabajadores (Infonavit y Fovissste2) padecieron una descapitalización paulatina desde su creación en los años 1970. En paralelo, la política de redensificación de la parte central de la ciudad con el decreto llamado «Bando 2» en 2000 (Tamayo, 2007) ha tenido ciertos logros, pero también ha impulsado un movimiento inverso con la fuga de la actividad inmobiliaria hacia las periferias más lejanas. Como resultado, los municipios de mayor crecimiento demográfico de 2000 a 2010 corresponden a los de mayor inversión inmobiliaria en conjuntos residenciales horizontales de bajo costo, en la periferia lejana de la urbe.

La política nacional de vivienda dio un giro desde la mitad de los años 1990 bajo las prescripciones del Banco Mundial, hacia una acción enfocada al desarrollo del libre mercado. En materia de vivienda de bajo costo, los organismos públicos producían y administraban unidades residenciales verticales concebidas bajo el modelo europeo de los grands-ensembles. Desde luego, la producción directa de vivienda fue cambiada por medidas de estímulo de la actividad privada por medio de un conjunto de acciones y garantías, así como de canalización de la demanda para un prototipo de vivienda normalizado por el Estado. En cambio, los organismos públicos han reducido su vocación inicial, la provisión de vivienda, y se han enfocado en la gestión hipotecaria de los créditos sociales otorgados a sus

1 Usamos la expresión «interés social» con cautela: es empleada por el gobierno mexicano como simple etiqueta, pese a que este tipo de vivienda canalice subvenciones muy simbólicas del Estado. La vivienda «de interés social» es en realidad un segmento de bajo costo de la vivienda del sector privado, en accesión a la propiedad, con un valor comercial controlado.

2 Respectivamente: el Instituto del Fondo Nacional de Vivienda para los Trabajadores (para los empleados del sector privado), y el Fondo de la Vivienda del Instituto de Seguridad y Servicio Social de los Trabajadores del Estado (para los empleados del sector público). 
derechohabientes y a la colaboración al diseño de leyes nacionales de vivienda. En respuesta a las condiciones muy favorables de inversión, los grupos inmobiliarios concentraron la gran parte de su actividad en la vivienda «de interés social».

Del año 2000 hasta hoy, con el motivo de responder a la demanda de vivienda pero también para impulsar a un sector clave de la economía, la construcción, el Estado siguió flexibilizando las condiciones de acceso a las hipotecas para la comercialización de vivienda de interés social. Los hogares de menores recursos (de 2 salarios mínimos3) hasta los salarios más elevados pueden beneficiar de un crédito por parte de los organismos públicos. En cambio, el aumento constante año tras año del número de créditos otorgados para vivienda económica ha constituido una fuente de publicidad importante para el partido en el gobierno de 2000 a 2012 (el Partido de Acción Nacional). Las acciones para sostener este crecimiento culmina con el fin del mandato de este partido en 2012, pese a la evidencia de un modelo urbano inadecuado. Se puede hacer un paralelo entre las elecciones presidenciales del mes de julio de 2012 y una importante reforma de la ley del Infonavit a principios del mismo año que permite la adquisición de una segunda vivienda con las mismas condiciones preferentes, una vez cubierta la primera hipoteca. Esta medida, no cuestionada por ningún medio, parece garantizar la multiplicación a largo plazo de la demanda y la continuidad de un modo de producir la ciudad.

El conjunto de estos factores ha orientado la gran mayoría de la oferta de vivienda de bajo costo adonde los grupos inmobiliarios tenían o formaron sus reservas de suelo, es decir, donde fuese más rentable. Una dinámica de urbanización de «casitas» se desenvuelve entonces desde 1993, fuerte consumidora de espacio donde dominan los terrenos rurales en declive lejos de la metrópoli. La localización de los desarrollos no se vincula con la cercanía métrica de la urbe, pero sino por una relación reticular (Monnet, 2010): se sitúan con una cercanía relativa con respecto a las autopistas radiales. Más periférica sea la ubicación sobre el sistema vial, más alargadas son las horas pico, lo que vuelve la experiencia de movilidad particularmente problemática. Estimamos la población que vive en conjuntos urbanos a unos 3 millones de habitantes a finales de 2011, lo que equivale a casi 15 \% de la población metropolitana. Las proporciones del fenómeno ya han alcanzado los límites geográficos de lo practicable para sus habitantes. Aun así sigue esta dinámica de urbanización, que solo contrarrestaría un cambio drástico de política.

La política de fomento a la vivienda no se acompaña de la inversión pública suficiente en términos de infraestructura. Hacia las zonas norte y oriente de la urbe, se ha implementado la construcción de una red de transporte masivo, la cual quedó en quiebra antes de concluirse, perjudicando directamente las partes más periféricas de la metrópoli. Las operaciones de vivienda de interés social se apoyan entonces en las infraestructuras viales existentes, como principal, por no decir única, infraestructura ofrecida a los pioneros de estos conjuntos

3 El salario mínimo mensual se emplea como unidad de cálculo, un SM equivale a 1900 pesos mexicanos en enero de 2012 (148 USD). 


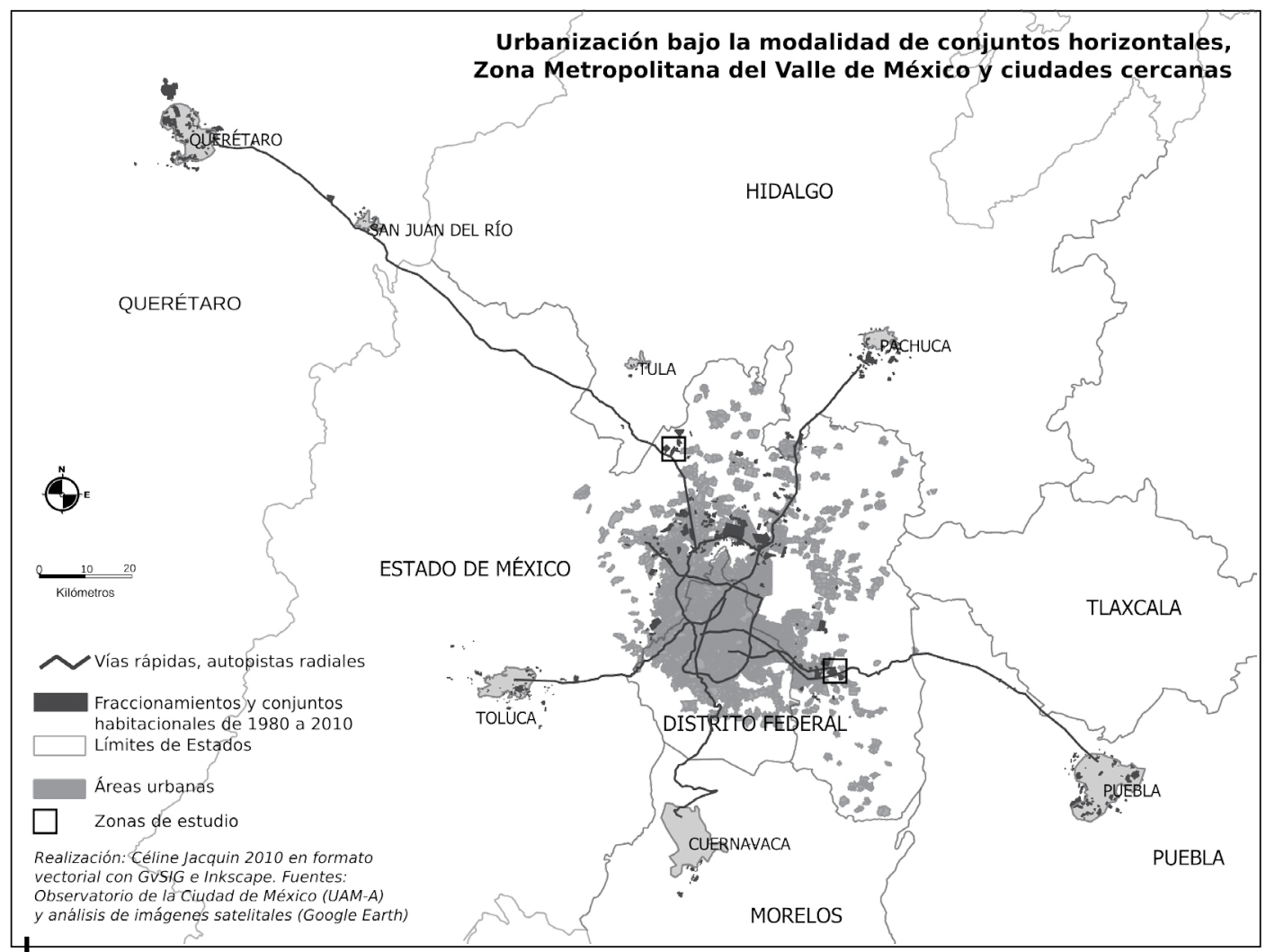

Figura 1 - Distribución de la urbanización estandardizada horizontal en la zona metropolitana del Valle de México

residenciales. Al contrario, estas operaciones presentaron graves lagunas en materia de equipamientos, de infraestructuras básicas y de recursos ambientales. En este aspecto abundan los escándalos sobre el agotamiento de recursos en agua, sistemas de drenaje subvalorados y mal construidos, etc. El tipo de conjunto residencial producido masivamente responde a una normatividad rígida aunque preferente para los desarrolladores. Tiene como consecuencia el desarrollo sin variación de un mismo producto por todos los grupos inmobiliarios. El «conjunto urbano» es horizontal y se compone de un solo tipo de construcción: viviendas dúplex alineadas con muros compartidos, con uniformidad arquitectural, una densidad alta de viviendas, una proporción baja en equipamientos urbanos, y una agrupación de secciones de menos de 4000 viviendas. Los conjuntos contienen en promedio 3000 viviendas, y como máximo unas 20000 viviendas en diferentes secciones. Declinan sin mucha variación un diseño interior estructurado por calles cerradas con hasta 60 casas alineadas unidas por avenidas en circuito, en un solo conjunto o más frecuentemente en secciones sin coherencia espacial. Las viviendas de interés social miden alrededor de 50 metros cuadrados en dos niveles. La planeación es delegada en su totalidad a las empresas inmobiliarias, 
de tal modo que los preceptos de plusvalía son los que rigen: la vivienda y el conjunto urbano son concebidos con una inversión minimalista, con ahorro de materiales, así como las infraestructuras y acabados. Los espacios públicos reciben un trato equivalente (ver Maya \& Cervantes Borja, 2005).

La instalación de miles de hogares en lapsos promedios de 6 meses significa para los municipios de destino una explosión demográfica contundente, habida cuenta que dominan los territorios de tipo rural, poco poblados, con finanzas municipales que no llegan a la medida de los problemas urbanos y sociales que se presentan entonces. El perfil socioeconómico y la identidad de los municipios cambia también de forma drástica, como resultado de la instalación masiva de las nuevas poblaciones de propietarios, al pasar de un perfil rural con poca relación con la metrópoli a una población mayoritariamente originaria del Distrito Federal (DF) y de la periferia consolidada. Las nuevas poblaciones periféricas por fin, aunque relativamente pauperizadas, tienen recursos superiores al nivel de los municipios receptores, benefician de prestaciones sociales (como de salud, de jubilación y de apoyo a la vivienda), y tienen niveles educativos más elevados. Estas características legitiman en muchos municipios el reservar aún más las acciones públicas locales a otros espacios más carentes en todos aspectos. Al contraste social fuerte se suma para los nuevos hogares un aislamiento físico con el territorio local y con el resto de la metrópoli (Duhau \& Jacquin, 2008).

A la insularidad física ligada a la concepción de los conjuntos urbanos, se suma una ruptura vivida, ilustrada por las prácticas espaciales de los nuevos habitantes.

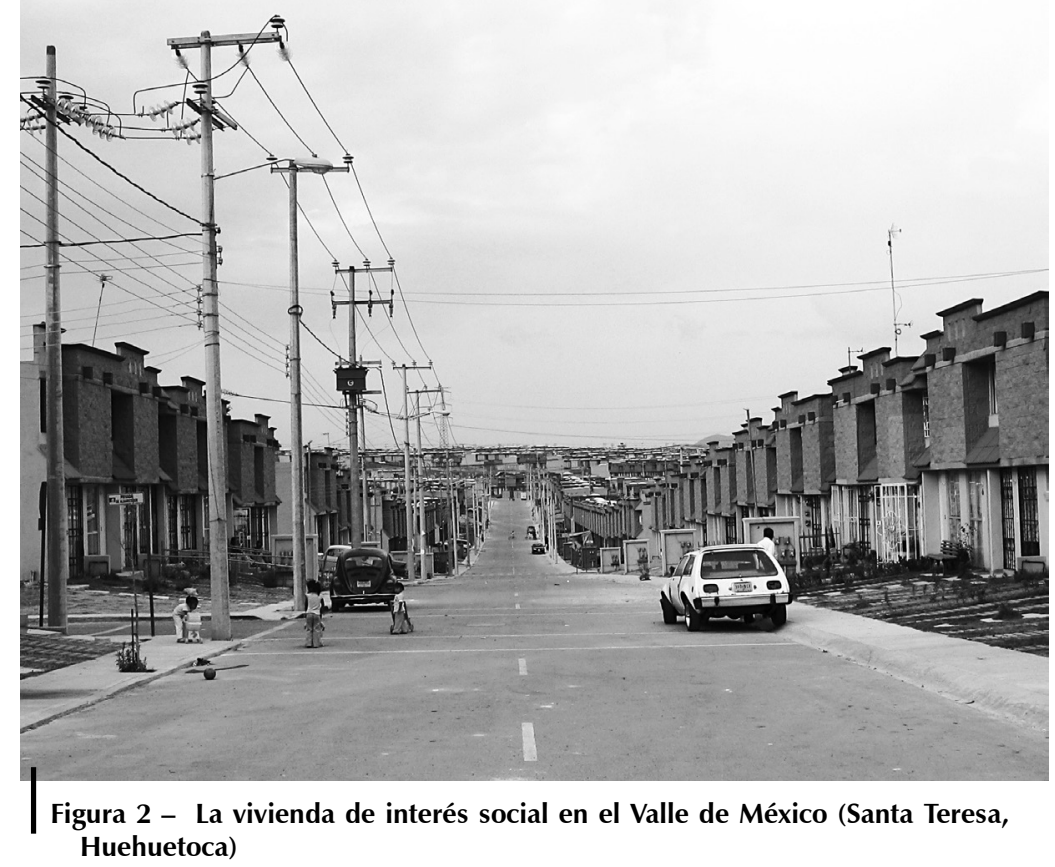

Foto Céline Jacquin, 2009 
Las movilidades regulares de los habitantes de San Buenaventura y Santa Teresa, comparadas con las de los habitantes del municipio, atestiguan fuertes contrastes. Los habitantes del municipio revelan un arraigo local en todas sus dimensiones: empleo, ocio, servicios, sociabilidad. En cambio, las prácticas de los nuevos habitantes demuestran una fuerte ruptura con el territorio local: en los dos conjuntos estudiados, se observa una relación duradera con el barrio donde se vivía anteriormente. En San Buenaventura, una década después de la instalación, las prácticas urbanas en el municipio siguen siendo muy secundarias frente a las dirigidas hacia las áreas de origen, donde se ubican además los parientes. Los traslados de ocio, que consisten en su mayoría en visitas a los familiares, se concentran allí. El mismo arraigo se verifica a lo largo de la trayectoria residencial. Al responder a la pregunta sobre la ubicación ideal en la ciudad, si pudieran mudarse sin limitación económica alguna (como parte de la encuesta por cuestionario desarrollada durante la investigación), la mayoría de los encuestados no mencionaron las zonas más agradables y selectivas de la ciudad, sino las zonas donde vivían anteriormente y donde viven sus familiares más cercanos. Los dos tercios sin embargo respondieron que no se mudarían del conjunto residencial.

En efecto, las características de las viviendas y de los conjuntos consideradas por observadores exteriores (los académicos, el periodismo, la opinión pública) como desastrosas, resultan generar una satisfacción tal para los habitantes en general, que matiza el peso negativo del alejamiento. Al depender la localización del mercado privado de vivienda, y de la canalización directa de la demanda hacia las empresas inmobiliarias, esta es rara vez elegida para este segmento de la sociedad. En realidad esta condición es propia del sector popular incluso en otras formas de urbanización, para el cual una localización no favorable se equilibra generalmente con el agrado de haber accedido al patrimonio.

\section{PRECISIONES METODOLÓGICAS Y DATOS CLAVE}

Este trabajo retoma algunos datos de mi investigación de doctorado en Estudios urbanos. La investigación pretende alimentar el debate sobre la periurbanización de las metrópolis, al mostrar los impactos de la política «viviendista» en México sobre las prácticas urbanas y las trayectorias familiares desde su instalación en las periferias recientes de la Zona Metropolitana del Valle de México.

Los datos recabados provienen de un trabajo de observación participante por inmersión entre 2007 y 2009 en dos conjuntos residenciales de bajo costo en la Zona Metropolitana del Valle de México. Se desarrolló en este periodo una encuesta por cuestionarios en 500 hogares y cincuenta y cinco entrevistas a profundidad. Ambos conjuntos residenciales son característicos de la categoría de vivienda de «interés social» Ilamada «conjuntos urbanos», creada en 1993. Se eligió para el trabajo de campo el conjunto urbano más antiguo existente y uno de los más recientes en el inicio del trabajo de campo, representativos de las problemáticas territoriales de la metrópoli. Los datos han sido cruzados con distintas encuestas de gran amplitud del 
Inegi4. Cabe señalar que los hogares que acceden a la vivienda de interés social, por mecanismos propios al sistema hipotecario, revelan una gran homogeneidad de perfil según criterios de edad, tipo y composición de hogar, nivel socioeconómico, así como de proveniencia geográfica.

El primer conjunto urbano, «Santa Teresa» se encuentra en el municipio Huehuetoca (extremo Norponiente de la zona metropolitana), desarrollado en secciones por la empresa Homex a partir de 2003. Es el primer conjunto de esta medida en este municipio. A finales de 2009 se construyeron 19955 viviendas sobre una extensión de 332 hectáreas, y prosigue su desarrollo.

EL $21 \%$ de sus habitantes provienen de la parte central de la metrópoli (DF); el $81 \%$ de municipios conurbados colindantes al DF; 9 \% de Huehuetoca o de los municipios colindantes.

Más del 90 \% son hogares nucleares simples completos (una pareja con hijos), el 80 \% están compuestos de 4 a 5 individuos. La pirámide de edades muestra claramente dos grupos: 4-15 años, y 35-40 años.

El conjunto urbano San Buenaventura, en cambio, es el primer espécimen de conjunto residencial de la categoría «conjunto urbano». Se localiza en el municipio de Ixtapaluca (extremo Oriente de la zona metropolitana, en parte consolidado), fue desarrollado en secciones por el Consorcio Ara a partir de 1997 para 20342 viviendas, sobre 252 hectáreas. Se encuentra totalmente comercializado y habitado desde más de diez años.

El $39 \%$ de sus habitantes provienen del DF; el 43,5\% de Ixtapaluca, de los municipios ubicados entre Ixtapaluca y el DF, o de los estados cercanos; el $15 \%$ de municipios alejados. Como el municipio de Ixtapaluca forma parte del primer contorno periférico que recibió el crecimiento urbano espontáneo a partir de los años 1960, gran parte de los habitantes instalados en San Buenaventura provenientes del municipio había migrado del DF a este lugar en la generación anterior. Puede tratarse de un segundo movimiento centrífugo de migración metropolitana.

Más del 80 \% de los hogares de San Buenaventura están compuestos de 4 a 6 personas. Cerca del 90 \% son de tipo nuclear simple completos. Los hogares extensos se presentan en proporción más importante que en Santa Teresa, con la presencia de parientes: nietos, padres, u otros.

\section{SIGNIFICADO DE LA VIVIENDA PARA LAS FAMILIAS PIONERAS}

\section{1. La generación del ciclo ascendente}

Desde la mitad del siglo pasado, el proceso de crecimiento de la ciudad toma principalmente la forma de colonias irregulares fraccionadas, donde los colonos

4 El Inegi es el organismo a cargo de producir y comunicar estadísticas de población, vivienda y economía. 
autoconstruyen sus viviendas y participan en la construcción de las infraestructuras, aportando mano de obra al esfuerzo de los ayuntamientos para dotar en servicios básicos estos nuevos barrios. Los colonos habitan con gran precariedad su vivienda, barrio y la ciudad5, a lo largo de muchos años de negociaciones con el Estado y trabajos comunitarios antes de lograr un espacio barrial satisfactorio. Por ende se sufre durante una larga fase de consolidación, la inexistencia y luego la inadecuación e insuficiencia de los sistemas de drenaje, de agua, luz, calles en terracería. Años después, con casas construidas, estas colonias siguen muy pobres en término de espacios públicos, recreativos y equipamientos en general, ya que la traza urbana no ha resultado de ninguna planeación y ha seguido extendiéndose.

La precariedad para los colonos de las colonias de autoconstrucción reside en la ruptura social vivida al instalarse. El acceso a un terreno en un fraccionamiento irregular es consecuencia de una red relacional que opera como canal de información. Pero no siempre significa una cercanía geográfica del terreno con esta red. La instalación implica un tiempo de adaptación y la re-creación de las redes sociales así como de las relaciones de solidaridad cotidiana. En un contexto de muy baja movilidad residencial a escala de las generaciones, este cambio es vivido como un evento clave y una crisis fuerte en la trayectoria familiar.

Los hogares que entran en el proceso de autoconstrucción son formados mayoritariamente por parejas jóvenes con hijos pequeños, los cuales tuvieron que salir de su hogar de origen por falta de espacio o migraron desde la provincia a la ciudad. En muchos casos se suman al hogar parientes que pueden participar al gasto de producción de la casa, así como lo harán los hijos una vez adultos. Como parte integrante del proceso, ellos heredan de un espacio construido en el terreno para alojar a sus propias familias (ver sobre estos procesos: Hiernaux \& Lindon, 2003). El proceso relativo a la producción de la vivienda se imbrica fuertemente con las lógicas familiares, de forma muy perceptible en los grupos populares donde la falta de recurso obliga a unir esfuerzos, y significa interdependencia entre individuos y generaciones. Esta red tiene como núcleos irreductibles hogares de tres generaciones (Adler de Lomnitz, 1993).

La vivienda autoconstruida se apoya sobre ciclos de acumulación colectiva de bienes que define, además de la posición en la familia, el derecho de cada miembro de la familia a pretender una parte del terreno o de la construcción. La vivienda se amplia y se mejora de este modo con lentitud, durante hasta varias décadas hasta no tener cupo. El núcleo familiar empieza entonces a expulsar una parte de los hijos, los cuales quedan en busca de un lugar para la creación de un nuevo núcleo familiar. Esta generación «saliente» tiene la opción —mucho menos favorable hoy día- de buscar un terreno en un fraccionamiento irregular, o si es beneficiario de prestaciones sociales, orientarse hacia una vivienda de interés social «terminada» en un conjunto residencial. El itinerario de estos grupos

5 La idea subyacente al habitar refiere a la acción de ocupar una vivienda pero también al apropiarse del espacio en varios usos y en varias escalas como la del barrio, del municipio, de la ciudad, y el conjunto de lugares que toman un sentido para los individuos. 
y generaciones específicas les forja una percepción del lugar de vida y de la propiedad, así como normas de habitar que reflejan el valor del trabajo paulatino y del sacrificio en el objeto de la vivienda. Este bagaje lleva la dimensión de la propiedad muy encima de lo cotidiano. Además, comparado con las condiciones de vida que conocieron anteriormente con sus familiares, la vivienda de interés social es fuertemente apreciada por la casi totalidad de los encuestados, por su estado de construcción al momento de la adquisición y un diseño considerado como símbolo de modernidad y estatus.

\section{2. Trayectoria y urbanidad}

El origen social y la trayectoria urbana de los habitantes observados conllevan una muy baja movilidad residencial en el pasado. Casi todos los encuestados crecieron y se juntaron en matrimonio en casa de sus padres o suegros; una mayoría de las familias solo conoció una misma zona de la ciudad antes de llegar a su nueva casa. La mitad de los encuestados se han independizado de sus padres y transitado por varias viviendas en alquiler, con toda la inestabilidad que supone la condición de inquilinos en un contexto muy poco regulado. En todos casos gran parte de ellos permanecieron en un área de proximidad que tiene como retícula la familia. Los hogares que han vivido en zonas muy variadas de la ciudad, no dejaron de apoyarse en la red familiar. Cual sea el grado de movilidad geográfica, muy pocos se han salido de este sistema socio-espacial. La ruptura es inédita con la instalación en el nuevo conjunto residencial. Casi todos (las mujeres en especial) expresan haber vivido con gran dificultad la separación de la red familiar, una soledad nunca conocida antes y frecuentemente acompañada de depresión. Pero también se tiene conciencia de que es un paso normal, el mismo que han vivido sus padres al independizarse para construir un nuevo hogar en las colonias donde autoconstruyeron. En esta introspección, comparado con los miembros de la misma generación que sí heredaron de un espacio en el terreno paterno, los encuestados expresan la dificultad, y cierta injusticia por ser la generación saliente. Pero también, esta independencia es fuente para el conjunto de los encuestados de un claro sentimiento de libertad. Todos expresan haber vivido después de un tiempo de adaptación una etapa nueva y positiva en la vida de pareja y como padres, a consecuencia de la adquisición de la casa.

6 Cabe mencionar que las encuestas desarrolladas por otros investigadores han dado en ocasiones resultados distintos respecto a la satisfacción residencial de los nuevos propietarios de este tipo de vivienda en México. Asimismo constatamos fuertes contradicciones en el discurso de los habitantes según la técnica de encuesta utilizada. Las entrevistas no a profundidad y enfocadas a condiciones de habitabilidad de la vivienda y del conjunto urbano producen regularmente discursos negativos. Este tipo de entrevista ubica a los encuestados en el registro de las carencias y apunta a la experiencia inmediata de dificultad. Mientras tanto, las entrevistas a profundidad y con vista a sus trayectorias de vida manifiestan una satisfacción notoria en numerosas dimensiones y a lo largo del tiempo, desde la instalación, en el momento presente y hasta como se proyectan en el futuro, pese a que se reconocen los problemas debidos a este tipo de urbanización. 


\section{Cuadro 1 - Cohabitación familiar}

El $31 \%$ de los encuestados de San Buenaventura y el $25 \%$ de Santa Teresa vivían en una casa compartida con sus familiares antes de adquirir su casa. El $55,5 \%$ y el $50 \%$ en una vivienda independiente en el mismo municipio que sus padres/suegros. El 9 y el 8,5\% recíprocamente declararon vivir en una casa prestada, oportunidad regularmente dada dentro del círculo familiar.

$\checkmark$ En los dos conjuntos residenciales, el $75 \%$ de los encuestados están satisfechos o muy satisfechos de sus condiciones de vida comparadas con el domicilio anterior. El 20 y el $30 \%$ no destacan ningún cambio significativo. El $3 \%$ y el $12 \%$ consideran que su situación ha empeorado. Esta última proporción se vincula a las condiciones del hábitat en el conjunto más reciente, en el cual faltan muchos servicios todavía.

$\checkmark$ Para el $43 \%$ de los encuestados (en igual proporción en los dos conjuntos) la propiedad y la independencia resultante para ellos como matrimonio y familia es el mayor criterio de satisfacción de la nueva vivienda.

Según perciben casi todos los encuestados, pese al espacio muy reducido, las viviendas de interés social constituyen una enorme mejora material comparada con sus condiciones de vida anteriores y de la infancia. El conjunto tiene desde un principio todos los servicios básicos a la diferencia de una colonia invadida. Pero un criterio todavía más relevante es el sentimiento de encontrarse con colonos de «otro tipo»7 social que los pioneros de las colonias populares de donde provienen, y con otra actitud y visión hacia la colectividad: así consideran que los residentes del conjunto urbano se comportan con respeto, las relaciones son más anónimas e independientes. Ahí la gran homogeneidad de aspiraciones participa en el sentimiento de logro del proyecto de ascenso social de los hogares. Las normas compartidas favorecen una identificación paulatina con el vecindario y el barrio para esta generación de pioneros. La simetría de estatus (como propietarios) y su papel en el desarrollo de sociabilidades afines fueron observados en varios estudios sobre los barrios de clases obreras (Cartier et al., 2008; Young \& Willmott, 1983; Chombart de Lauwe et al., 1960).

Por otro lado la percepción positiva del conjunto se debe al valor dado a la propiedad de la vivienda, en un contexto de fuerte inestabilidad económica a lo largo de sus vidas, sobre todo para las familias que han experimentado el arrendamiento de vivienda, con las condiciones precarias que implica. Los precios de la vivienda en alquiler en la ciudad de México rebasan generalmente el monto del reembolso de la casa de interés social. Las parejas con niños atestiguan el haber vivido en estas ocasiones en uno o dos cuartos en casas ajenas compartidas, sin autonomía y con el temor constante de una alza repentina de alquiler o de un despido sin aviso previo. La adquisición se acompaña frecuentemente de cierta lucidez sobre la baja calidad constructiva del producto residencial adquirido,

\footnotetext{
7 Las expresiones entre comillas corresponden a enunciados frecuentes de los entrevistados.
} 
y sobre la necesidad de una inversión paulatina para mejorar y mantener estas viviendas, lo que no disminuye realmente la satisfacción residencial. Se reproduce una representación del espacio que subraya la falta de control sobre su entorno, tal como se vive en los barrios informales donde las posibilidades de mejora son bastante aleatorias. Como fruto de sus experiencias pasadas, la dimensión fortuita y temporal del estado de los lugares es asimilada por la mayoría. Ellos suelen considerar que ningún espacio puede permanecer mucho tiempo en buenas condiciones debido a lógicas ordinarias de desorganización política y de falta de consenso social. Todo barrio parece condenado a degradarse - en su apariencia, en la cualidad de los servicios, su «ambiente social» y seguridad- tras el paso de las generaciones y su densificación, y el conjunto residencial no debe ser la excepción pese a su aspecto planeado y controlado en un inicio.

Con esta visión hacia una realidad huidiza, el discurso de los habitantes apunta al deseo de gozar de la etapa inicial - muy temporal- del barrio. Apostan en este lapso a un espacio preservado para sus hijos, por lo menos una parte de su infancia. Subrayando nuevamente que la escala de tiempo de referencia para la apreciación del lugar de vida, debido al estatus de propiedad, es el tiempo largo, esta consideración no disminuye su satisfacción residencial. Por otro lado, se asimiló que no existe elección del lugar de vida y que uno debe contentarse con las oportunidades recibidas, y aceptar los límites propios a los lugares a su alcance. Es común la expresión de resignación hacia la experiencia cotidiana, condicionada aquí por la lejanía, «hay que aguantar... porque no hay de otra». En este sentido, la estrategia de los pocos que pueden volver a «elegir» su ubicación para una segunda vivienda es reveladora. La situación económica del hogar permite en algunos casos la compra de una segunda casa, o bien algunos hogares deciden traspasar su vivienda para adquirir en otro lugar. Es interesante observar que la elección tiende hacia un producto estrictamente equivalente en otro conjunto urbano muchas veces más reciente. Este cambio se explica como una vuelta atrás en el tiempo, hacia la situación de un conjunto residencial nuevo, carente de servicios y comercios pero también de degradación material y social, con el fin de volver a gozar este estado de tranquilidad. Los habitantes enuncian claramente el deseo de vivir un tiempo más las condiciones de orden y limpieza, aunque tampoco allí deba durar.

La homogeneidad de trayectorias, de nivel social y de aspiraciones, explican un estado de satisfacción general. La similitud de situación de la población de los conjuntos, ubicados en una misma etapa del ciclo familiar, produce cierto consenso sobre la necesidad de preservar, o producir un espacio ameno, capaz de arraigar a la generación siguiente y asegurarse un espacio en el nuevo hogar que pronto será encabezado por los hijos. Casi todos los entrevistados presentan la vivienda como la de sus hijos. Ellos se proyectan en el lapso de una década hacia la situación de dependientes económicos. Imaginan a sus hijos viviendo en la misma vivienda ampliada o no, o en una vivienda adquirida cerca en el mismo conjunto residencial. 
El punto de inflexión en la trayectoria urbana individual y familiar que representa la adquisición de la vivienda en los conjuntos residenciales periféricos, implica una fragilidad existencial en esta generación, conlleva dificultades cotidianas y sacrificios, pero globalmente eleva sus condiciones de vida en un largo plazo. Pero sobre todo, esta situación marca el inicio de un nuevo grupo familiar plurigeneracional que determina el futuro de esta generación como individuos mayores de edad.

\section{ABNEGACIÓN Y CONTRASTES DE GÉNERO}

El proyecto patrimonial se logra al precio de un cotidiano difícil en sus dimensiones económica, social y funcional, lo cual no se debe subestimar, y que implica la movilización de los individuos a través de una división de papeles aún más aguda que la tradicionalmente establecida. Cabe puntualizar que la situación económica al instalarse como propietarios y en conjuntos residenciales donde al principio el transporte es insuficiente e impone precios altos por aprovecharse de una demanda cautiva, hace que las parejas se concentren en el empleo más provechoso. Considerando el salario promedio de los jefes de familia en Santa Teresa (2 salarios mínimos en promedio), su gasto en transporte alcanza el $35 \%$ del ingreso del hogar. Las mujeres, quienes para un mismo cargo tienden a ganar menos, no encuentran interés en conservar un empleo que las aparta de su hogar. La mayoría de las que tenían un empleo antes de mudarse lo abandonan al instalarse, considerando que casi todas tienen hijos y que ya no pueden contar con apoyos familiares.

La distancia y las dificultades económicas acentuadas hacen del hombre el preso de una movilidad pendular. En el contexto económico de estos municipios, en unos casos muy poco urbanizados y poblados, en otros más densos pero con una economía terciaria autogenerada y con niveles de salarios muy por debajo de los existentes en la parte central de la ciudad, los habitantes de los nuevos conjuntos residenciales conservan en gran parte sus empleos en el DF o en el primer contorno periférico donde se concentran las industrias. Estas dimensiones refuerzan a su vez la división de los papeles de género y el arraigo de la mujer en su hogar. Por otro lado, la pauperización temporal o duradera ligada a la adquisición de la casa y la instalación de las familias, acentuá el papel social de la mujer.

\section{1. Territorialidades masculinas discontinuas}

Más allá de la vivienda y del conjunto, las configuraciones geográficas y económicas del municipio constituyen una franca desventaja frente a las vividas por la generación anterior en los barrios de autoconstrucción. La falta de empleo en los alrededores se suma a las extensiones siempre mayores de la urbe, que hacen sus márgenes en crecimiento siempre más inaccesibles, y encierran a los jefes de familia en un cotidiano reducidos a su movilidad pendular. 
Así, los hombres atestiguan de un inicio difícil en el conjunto. La contrariedad es fuerte, pero la necesidad de «seguir adelante» y luchar contra la desesperanza les da una postura de autocensura. En estos casos no se puede hablar de adaptación, sino solo de resignación y automatismo: el margen de control de su cotidiano es totalmente limitado a la actividad laboral, la cual tiene el deber de conservar. Su papel de jefe de familia8 y sostén económico es objeto de fuertes presiones, que genera aquí un nivel particularmente elevado de agobio y frustración. Para no someterse al juicio de sus seres cercanos, los hombres evitan expresarlo (Gutmann, 2006).

El nivel de dificultad cuando es extremo, tiene aquí como efecto el agudizar la distancia entre los géneros, llevando a una desconexión emocional dentro de la pareja. Se constata la costumbre en el hombre como en la mujer, de autoreprimir las dificultades ligadas a su papel de género. En lo que concierne a las mujeres, se considera que el gran esfuerzo sustentado por el hombre para adquirir y financiar la casa no debe ser menoscabado con quejas. Esta necesidad es tradicionalmente desplazada hacia personas que se adecúan con el papel de confidentes: las demás mujeres de la familia en forma virtual o, más accesibles, las vecinas. En lo que atañe al hombre, parece no corresponder con su papel la posibilidad de la duda y de la lasitud. Cada uno considera que su pareja carga con suficiente presión y trabajo. En lugar de buscar apoyo moral entre la pareja, se asume entonces una total disociación entre el ambiente de afuera y el ambiente del hogar, el cual se busca preservar de la dura realidad. En muchos casos, las esposas minimizan claramente o admiten desconocer las dificultades cotidianas de sus esposos porque ambos evitan este tema, o asumen que el otro no tiene problema alguno.

En estas condiciones de dedicación exclusiva al trabajo, la experiencia de lo cotidiano de los jefes de familia depende de unos factores no controlables, como la calidad del servicio y de la infraestructura de transporte, incompleto, carencial, en territorios subdesarrollados o al contrario muy densos y saturados. Cualquier variación horaria en el empleo tiene a su vez un impacto decisivo en las sociabilidades que pudiera llevar a cabo el jefe de familia. Los hombres que trabajan en el Distrito Federal o en sus alrededores - es decir la mayoría de ellos - viajan entre dos y tres horas de ida, o menos si pueden evitar las horas pico cuando trabajan a turnos9. En los conjuntos urbanos estudiados, donde los jefes de familia son en mayoría obreros o poco calificados, esta situación laboral es bastante común. Las prácticas de movilidad resultantes provocan un desfase con los ritmos ordinarios de su contexto social y familiar.

8 En los dos conjuntos urbanos estudiados, el $87 \%$ de los jefes de familia son de sexo masculino, según la libre declaración de los encuestados entre jefe de familia y cónyuge. Esta cifra rebasa de mucho las cifras a escala nacional y de la Zona Metropolitana del Valle de México: 75 y $73 \%$ (Inegi, 2010).

9 Los hogares estudiados son en gran parte encabezados por hombres obreros. Las condiciones tradicionales del trabajo industrial los lleva a trabajar por turnos: se trata de una forma de organización del trabajo en equipo según la cual los trabajadores ocupan sucesivamente los mismos puestos de trabajo sobre 24 horas de actividad. Regularmente, un mismo trabajador dobla el turno, y sus horarios cambian cada quincena. 
Extracto de entrevista: Rodolfo, 43 años, San Buenaventura, tres hijos, obrero. Tuvo dos empleos diferentes desde que se instaló, uno con horarios normales que implican traslados en horas pico, y el actual donde trabaja por turnos.

«La verdad, antes yo salía mucho a distintos lugares por aquí cerca, a jugar fútbol, o qué sé yo. Pero últimamente ya no, porque ya... ya no me da tiempo por lo mismo que ya... me vengo a dormir ya un poco tarde, y al rato me voy a trabajar. [sale] Muy poco, muy poco, por el tiempo del trabajo. - Entonces iera mejor antes [de que cambiará de empleo]? ¿A pesar de que se trasladaba más tiempo? - sí porque no trabajaba sábado y domingo. (...) Cuando llego ya están dormidos todos. Y hay días que me voy temprano, ya ni los veo. Hay veces que no los veo varios días de corrido. Voy a la una, ellos llegan a la una y media. Llego yo a las 12 ya están dormidos. Y es como no los veo casi toda la semana.»

«-iY usted cómo se relaciona con la gente aquí? - No me da tiempo, por el trabajo (...) Porque... estoy en la mañana, convivir con las personas, con los hombres... a veces están trabajando, a veces se van por otros lados... casi no. - O sea que iusted no tiene amigos aquí? - Pues... - (la esposa:) Solamente el vecino de en frente, bueno, que ahorita por el momento no están viviendo aquí... - Ah, ¿no vive aquí? Anteriormente sí. Se cambiaron por esta misma situación, que para irse a su trabajo le queda más retirado. (...) - ¿Como vive el no tener unas personas, a parte de la familia, con quien convivir? ¿Amistades? - Fíjate que... a mí no se me hace, así, muy necesario tener amistades, o un amigo, no... - ¿O es más en el trabajo? - Mmm... Bueno aquí como tengo poco tiempo de estar trabajando, no tengo muchos amigos. Anteriormente donde trabajaba, sí. Tenía dos... dos, tres compañeros que ya... tantos años que ya... - ¿Y se dejaron de ver? - Sí. Ya no es lo mismo, ya afuera del trabajo ya no puedo llegar a verlos, ya no. Me impide... Ya no puedo.»

Según revela el testimonio, representativo de un perfil promedio, el jefe de familia se condiciona para satisfacerse con un círculo social bastante reducido, globalmente limitado al círculo familiar. Muestra que se prioriza la satisfacción del hogar antes que la suya. El costo y los tiempos del transporte tampoco le permiten tener actividades variadas, ni sus horarios realizar desplazamientos en cadena. El cansancio es fuerte y limita las motivaciones para aprovechar el tiempo en casa de otro modo que el puro descanso. Menos del $7 \%$ de los jefes de familia declaran tener otra actividad (de ocio, religiosa, o alguna actividad manual desarrollada como complemento económico). La mitad de ellos la realizan dentro del conjunto residencial.

Frente a la incapacidad de construir él mismo lazos sociales consistentes, y con la imposibilidad, por falta total de tiempo, de actualizar sus lazos familiares, el hombre depende totalmente de los lazos que crea y reproduce su esposa. Se han hecho muchos estudios en antropología social sobre el funcionamiento y la importancia en las comunidades populares de la relación de parentesco. También se ha observado cómo esta categoría de relaciones se desplaza al vecindario en caso de ruptura geográfica. Las mujeres son entonces el motor de este sistema (Young \& Willmott, 1983). Observamos los mismos mecanismos en el ámbito del área residencial nuevo. 


\section{2. Un espacio femenil de reproducción social}

Frente a estas dificultades el papel de género de la mujer se ve acentuado con una responsabilidad exclusiva en la educación de los hijos. Mientras que antes la cercanía directa con los familiares femeninos permitía compartir esta responsabilidad y por lo tanto les otorgaba tiempo para desarrollar otras actividades, ahora el alejamiento de sus redes sociales lo impide. Al desaparecer este recurso, la proporción de mujeres dedicadas al hogar aumenta.

\section{Cuadro 2 - Ocupación femenina en San Buenaventura y Santa Teresa}

$\checkmark$ La división de papeles de género se refleja claramente en los dos conjuntos
residenciales con la proporción de mujeres amas de casa. Es de $70 \%$ en los dos
conjuntos residenciales estudiados, y al $80 \%$ en Santa Teresa el conjunto más
reciente.
$\checkmark$ Una tercia parte de las mujeres no asalariadas declara tener algún tipo de
actividad económica. La mitad de ellas la lleva a cabo en su propia casa, y el $70 \%$
en un área incluida en el municipio de domicilio.
$\checkmark$ En San Buenaventura, diez a quince años después de la instalación, las mujeres
que llevan una actividad lucrativa presentan una proporción menor comparado
con el conjunto más reciente: el $14 \%$ de las amas de casa. Esto muestra que las
actividades «de apoyo» a la economía del hogar son en gran parte coyunturales y,
de no ser necesarias a la supervivencia, se abandonan. También se debe tomar en
cuenta la etapa en el ciclo de vida: en los conjuntos recientes llegan hogares más
jóvenes (30 a 40 años), con hijos pequeños que arraigan a las mujeres a la casa y
propician el desarrollo de actividades vinculadas con mayor razón al área local.
Después de unos años, pueden alejarse de casa y acceder de tal forma a un empleo
mejor retribuido.

Por otra parte el estatus de propietario le da un peso mayor al papel tradicional femenino, asumido por la mujer como una voluntad reafirmada de enfocar sus esfuerzos sobre la esfera del hogar. Esta nueva situación conlleva dos aspectos fundamentales: por un lado un sentido de deber aumentado hacia el cuidado del hogar («ya que es de uno»), ahora que se ubican en una tendencia de acumulación y sin recurso humano sobre el cual apoyarse para el cuidado de los hijos, la necesidad es más fuerte que nunca. La desconfianza hacia un entorno desconocido que representa potenciales riesgos para los hijos y la vivienda, así como el alejamiento del hombre, dan más responsabilidad a la mujer como guardiana del hogar. Por otro lado, el vivir en su casa propia se vincula simbólicamente con el alcance de una etapa nueva en el ciclo generacional donde la mujer de esta generación saliente es dueña en su hogar. Esta posición significa una entera autoridad frente a la jerarquía de mujeres con quien acostumbraba compartir el papel de ama de casa. El tener sola el dominio de los asuntos de la casa y de los hijos le da una nueva posición y una nueva postura, en la cual busca realizarse plenamente. Las mujeres que anteriormente trabajaban expresan cierta nostalgia 
de su vida económicamente activa, pero también un fuerte orgullo en su nueva condición de madre «de planta». Orgullo que puede revelar una autolegitimación de la situación actual, pero también el traslado del desarrollo de habilidades en el emprender cotidianamente la labor de administradora y educadora en su hogar, fuente a la vez de nostalgia y de plenitud. Concordamos con Ann Oakley (1974) para quien además de la ausencia de elección para gran parte de las mujeres hacia su «carrera» de ama de casa (valor colectivo construido como una necesidad para el bienestar de un hogar), su trabajo es desacreditado e invisibilizado por la sociedad, y es precisamente lo que propicia insatisfacción y alienación. Pero incluso en el caso de las que se desenvolvieron trabajando, no hay un deseo real de volver a un empleo de tiempo completo una vez aceptado la dedicación hacia el hogar. De hecho las mujeres que tuvieron una carrera profesional de cierto nivel, más que las que solo trabajaron temporalmente siendo soltera, son las que valoran su nuevo papel de ama de casa: reconocen en él algunas de las funciones laborales que movilizan ciertas capacidades e incluso que les permitieron desarrollar nuevas, mecanismos que se suele valorar en el ámbito laboral. Esto participa de un sentimiento de crecimiento, de elección consciente, y no solo de sacrificio de sí. Por otro lado ellas experimentaron que el ser mujer y madre, con necesarias rupturas en el tiempo de la carrera y con el paso de los años, constituye un límite en el ámbito laboral. Midiendo las dificultades de retomar su profesión, vividas como insuperables, muchas mujeres con un bagaje profesional justifican su elección de seguir como ama de casa o de contentarse con el desenvolverse en una actividad de complemento, con estatus comunitario por ejemplo.

Extracto de entrevista: Andrea,_40 años, San Buenaventura, 2 hijos, ex ingeniera mecánica, ocupada como promotora del PRI 10 en la temporada de elecciones municipales de 2009. Al instalarse en San Buenaventura, Andrea abandonó su trabajo de ingeniera mecánica. Siguió con su carrera profesional unos años cuando tuvo a sus hijos, con el apoyo de su madre y de su suegra con quienes vivió sucesivamente para el cuidado de sus hijos.

«Me llenaba mucho este trabajo, para mi era fascinante mi trabajo, y me fregaba de lunes a sábado (...) Y los domingo era: lavar ropa de los niños, dejar listo despensa, comida, limpieza, todo para dejar la semana lista, y otra vez a iniciar tu remoldelino. (...) Por decirlo llegaba yo a la cita en la noche para poner la lavadora, a las 4 de la mañana ya estabas cociendo tus frijoles, la comida para dejar la comida hecha. $\mathrm{O}$ sea, no queda de otra. Y los domingos sí dormía pero 5, 6 horas a lo mucho. (...) Y a parte para mí ya era fijo levantarme todos los domingos, y lavar, acabar 10-12 del día, toda mi ropa, y al centro comercial a surtir despensa, pañales, etc., y medio organizar tu casa.»

Al mudarse a San Buenaventura, el costo del transporte obligó que uno de los dos abandonara su empleo. Era consciente del sacrificio que hacía al poner de lado su profesión, que no le permitiría volver fácilmente por las actualizaciones frecuentes necesarias y el perjuicio hacia la mujer en recursos humanos, tal como ella lo

10 El Partido Revolucionario Institucional es históricamente el principal partido político mexicano, al poder durante 71 años. Como resultado de las últimas elecciones, vuelve a la presidencia a partir de 2012 después de dos mandatos cumplidos por el Partido de Acción Nacional. 
vivió antes. Aun así ella puso como prioridad su hogar en la fase de adquisición patrimonial, elección que asume.

« Te ocupa el tiempo y te llena saber que con menos dinero de lo que tenías antes, puedes organizar tu casa. - En realidad iestás haciendo un trabajo no? - iSí! De administración, finanzas, manejo de finanzas, administración, diseño de interiores, ide todo le hago! - Después de que tuviste un poco de depresión, ¿esto te ayudó? - Empecé... a ver: bueno, si tienes cierta cantidad, y si con esto logras librar la quincena o el mes que tienes, empezar a calcular por día, es un logro para uno, quiere decir que soy buena administradora. Es un incentivo y te motiva, a mi me llena mucho esto ¿he? - Es como fijar metas en un trabajo... - Sí, sí. Yo en el trabajo llevaba un... como una bitácora, ¿no? Una bitácora diaria, ¿no? De 11 tanto tenía que facturar 100 formatos, bajar y checar el almacén, de tanto a tanto (...) en mi casa igual: de tal a tal hora que mis hijos les lleve al kinder, de tal hora a tal hora a lavar y tender, regresan a tal hora, ya tiendo lavadora ya están comiendo, o sea yo no soy de ahhhhh [desesperarme]. Ya con cierta edad te vuelves un poco más tolerante, y como que le agarras un lado un poco más tranquilo a la vida... (...) Antes sí me desesperaba, no acababa y andaba de mal humor todo el día. Eso es lo que se vuelva tu satisfacción; ahorita dices: ya controlo mi casa, ya controlo mi limpieza, ya controlo las horas de lavado, ... controlas hasta los tiempos en los cuales haces tus actividades. Y esto es bueno, o sea la vida siempre tiene sabor, siempre y cuando lo valora uno, ¿no?»

Andrea se ocupa ahora en actividades comunitarias voluntarias o actividades que le dejan alguna remuneración de complemento: en la mesa directiva de la escuela, en acciones de ahorro popular, o como promotora de algún partido político, con la condición de que éstas no compitan con sus actividades del hogar.

Al goce de una nueva posición en la familia y su hogar, se suma el agrado del estatus de propietaria el cual, en una trayectoria social ascendente, pide y otorga otro papel social: el de reproductora social, de apoyo al esfuerzo patrimonial del marido, de apoyo al desarrollo de los hijos. Los hijos representan una ambición más claramente enunciada en la medida que la clase social es baja: ellos son un vector directo de ascenso social, y en esta cualidad representan un seguro en caso de dificultad en un futuro (De Singly, 2002). Comprobamos que las mujeres hacen del cuidado de sus hijos una meta central, y aclaran en todo momento que el patrimonio residencial es el de sus hijos. La crisis económica, y el punto de partida de estos hogares (nivel educativo de los adultos inferior a la secundaria para la mayoría y falta de patrimonio invertible por ser la generación saliente) dejan claro a sus miembros que no habrá superación social en su generación, y que la construcción de patrimonio material se limitará a la casa adquirida, y quizás ampliada en un futuro. El margen de desarrollo consiste entonces en la capacitación de la nueva generación.

La necesidad pragmática de impulsar el desarrollo de los hijos, heredarles un patrimonio, y así asegurarse su solidaridad y protección en la vejez, es enunciado como un cálculo de reciprocidad consciente y muy transparente. En un contexto socioprofesional donde la vejez es sustentada, en el mejor de los casos, con pensiones de jubilación muy justas para solventar una pareja, se cuenta implícitamente con que los hijos se hagan cargo de sus padres cuando lleguen en esta etapa. Las 
mujeres además, nunca se sienten a salvo de un eventual abandono de hogar por parte del esposo. Sus pocas capacidades profesionales, así como la falta de conocimiento para reivindicar legalmente sus derechos, hacen que las mujeres del medio popular urbano cuenten ante todo, principalmente sobre el apoyo de sus hijos. El temor por quedarse privadas de sostén económico es siempre presente y constituye un tema de intercambio privilegiado entre mujeres, de tal modo que no dejan de aconsejarse entre ellas y presionarse para «ganarse» a sus hijos. A su vez, la ampliación paulatina de la vivienda en un modo autoconstructivo para alojar al núcleo familiar hace imprescindible el aporte financiero de los futuros adultos. El bienestar material y duradero de la familia, simbolizado por la vivienda, hace del consenso y de la solidaridad los elementos primordiales de la educación dada a los hijos.

Hombres y mujeres recién instalados en los conjuntos residenciales periféricos se encuentran en un inicio arraigados en sus papeles tradicionales de género con un peso más fuerte que antes. Esta inflexión se ilustra con la conjunción de varias escalas de tiempo: se presenta como la bisagra en el ciclo residencial de varias generaciones en las familias extensas; es un punto de desequilibrio en la red familiar debido a la costosa accesión a la propiedad; y es a la vez un punto de refuerzo de los individuos alrededor del núcleo más reducido del solo hogar. Asimismo, parte de los factores derivan de la autonomía reciente frente al sistema familiar, vivida a la vez como liberación individual y como debilitación social. Esta nueva condición es tanto apreciada como sufrida. Se alude a la libertad inédita otorgada, así como al desarrollo emocional que esta hace posible en la pareja y el hogar, pero también determina su condición de vida y su condición de género al restarles recurso material y humano. La ausencia de elección hacia su entorno de vida es una experiencia ya vivida y asimilada, más bien es definida por circunstancias y soluciones de urgencia. A la diferencia de experiencias pasadas, que de mismo modo llevaban presiones para el jefe de familia, la propiedad es aquí fundamental, «ya es de uno»: por primera vez su trayectoria de vida es orientada hacia una perspectiva sólida, y esta salida tiene un alcance existencial fundamental.

\section{COMPETENCIAS SOCIALES, LA AYUDA MUTUA COMO MOTOR DE ESTRUCTURACIÓN SOCIAL}

La complejidad y la profundidad de la trayectoria según lo planteamos, instaura una postura positiva de los habitantes frente a las dificultades cotidianas. El jefe de familia, por su parte, tiene poco margen en su cotidiano para operar mejoras en su calidad de vida, si es que se propone mantener un nivel de recurso viable. Las únicas alternativas para ellos, observadas en los conjuntos residenciales (con un nivel de riesgo variable según la antigüedad del espacio residencial), es el renunciar a su empleo y buscar un trabajo en un área cercano, o bien aprovechar un despido para invertir la indemnización en la creación de un negocio. Las dos opciones son arriesgadas. En el primer caso, la oferta de empleo es muy débil en 
los municipios periféricos donde se construyen los conjuntos de vivienda, frente a la población densa que se instala simultáneamente en un corto tiempo, y el nivel de salarios queda muy bajo. En el caso de un despido, el trabajador no obtiene fácilmente un monto suficiente para el arranque de un comercio, aunque este se abra directamente en su vivienda. Todo riesgo de inestabilidad en el ingreso principal significa una dependencia más fuerte hacia la red social.

En este campo, la mujer es quien accede a un papel más complejo que antes, con la necesidad de planear la estrategia adecuada para mantener una red de solidaridad con el mayor potencial posible, y buscar formas de recurso extra, las cuales en algunos casos la motivan a salir del área circunscrito del hogar.

En los conjuntos residenciales mexicanos, la homogeneidad sociodemográfica y la simultaneidad de la instalación de miles de hogares, representa una dificultad: todos los hogares comparten las mismas necesidades inmediatas y no cuentan con redes sociales locales ni cotidianas ni con posibilidad de aporte. Pero esta proximidad situacional también representa un potencial.

El acercamiento a los vecinos toma la forma de un labor social a cargo de las mujeres, con un cálculo consciente: «solas, no la hacemos». La ausencia más pronunciada que nunca del esposo las obliga a formar más rápidamente un círculo sobre el cual poder contar mínimamente en caso de urgencia, así como para la administración de la economía diaria. Subyace la necesidad de colectivizar y así matizar el riesgo social, lo que a su vez es vector de comunidad. Estas estrategias no son propias de la situación periurbana sino del ámbito popular, tal como se ha observado antes por la antropología urbana (Adler de Lomnitz, 1993). Lo característico de la vivienda en conjunto residencial es que las condiciones extremas de pioneros agudizan el aspecto estratégico de las relaciones locales, y por lo tanto, ilustran de forma muy clara estos procesos.

En primer lugar aparece vital para los hogares el buscar otras fuentes de ingreso, o por lo menos compartir cierto margen de seguridad, entre varias. Las primeras estrategias apuntan a un intercambio no arriesgado que permita construir un grupo de confianza. En base al salario del esposo y al monto que se asigna a los gastos del hogar administrados por las cónyuges, ellas se esfuerzan para producir un excedente, aunque mínimo, y así formar poco a poco un «colchón» de seguridad. Este micro ahorro, no suficiente en sí para enfrentar una urgencia, tiene como objetivo la inversión paulatina en mecanismos de seguro social en su sentido más primario. Muy pronto después de la instalación y a través de sociabilidades ordinarias, se conocen paulatinamente los hogares vecinos, se accede a informaciones clave tales como les profesiones ejercidas, los cargos, etc., así como la viabilidad y las periodicidades (semanal o quincenal, es lo más común) de ingresos. Según sus propias condiciones al respecto, cada ama de casa puede administrar un sistema de reciprocidad. La parte de presupuesto que ella invertirá en intercambios de reciprocidad por medio del don-contra-don, es siempre función de la posibilidad de aumentar el ingreso de base, o del desarrollo de un círculo más amplio de deudoras (material o moral) sobre quienes contar en caso de necesidad. A su vez, se observa una combinación íntima de los registros 
de la amistad y de la economía familiar. Las relaciones construidas entre vecinas se estructuran esencialmente sobre la base de la insuficiencia de los recursos del hogar —en cantidad y frecuencia- y por ende de la solidaridad ordinaria. La cercanía geográfica de la residencia dentro del conjunto y de los niños en una misma escuela, así como un mismo nivel de dificultades y capacidades económicas, al permitir una justa reciprocidad en el intercambio, son criterios de acercamiento y de solidaridad. Por otro lado, la heterogeneidad en las periodicidades de ingresos de cada hogar es clave en el intercambio, puesto que genera una capacidad de liquidez en tiempos de austeridad para otros hogares y viceversa. Un hogar con una curva demasiada regular de ingresos, como por ejemplo un ingreso cotidiano siempre equivalente, no representa al contrario una ventaja en este sistema; dicho hogar tendría que trabajar activamente a la producción de un círculo de deudores, con el fin de poder contar con él en un momento dado de necesidad. Además de construir lazos de confianza, según lo demuestran las prácticas de reciprocidad, el prestar y recibir de vuelta un monto de dinero tiene como objetivo general el ahorro indirecto. Al no lograr implementar por sí mismo un ahorro significativo, se cuenta con esta práctica para destacar «a fuerzas» un excedente invertible en la casa o en algún bien necesario.

Extractos de entrevista: Claudia, Santa Teresa, 38 años, 2 hijos, ama de casa, un año después de la instalación

«Lo que somos nosotros tres y la muchacha en frente, Julia, nosotros somos ahorita juntas, (...) en cuanto a la amistad y en la ayuda económica también. Y moral. - iSe ayudan económicamente? - Las cuatro. Que les falta dinero, que si el jitomatito, que si el knorr-suiza que si la licuadora, que si la tapadera de la olla exprés... - Y ¿̇cómo se conocieron las cuatro? - Pues, te digo que por mi forma de ser, porque... pues nos conocimos porque cuando yo llegué aquí, a mí me gusta ser muy amiguera. (...) pues empecé a invitar a Guille, empecé a invitar a Julia (...)»

Rodrido y Graciela, Santa Teresa, 34 años, 2 hijos, vigilante en caseta de cobro en la autopista y ama de casa

« - (Rodrigo) Ahorita sí lo he sentido que de repente los últimos días de la quincena andamos: (....... comiendo lo que podemos, a ver que huevitos, que frijoles, que arroz. Y ya otra vez cobro, y otra vez [ella] llena el refri, compramos pollo, carne y ya empezamos otra vez a subir y ya casi el final otra vez bajamos, y así, pero... bueno, gracias a dios no nos falta de comer, y con sus amistades de ella también cuando hemos tenido la necesidad de pedir o algo, también nos apoyan: No, oye qué onda, que préstame 200 pesos... - (Graciela) Sí. Ya me presta, y así salimos de los días que nos faltan y ya. Y así nos la hemos llevado. - Tienen esta confianza. - Sí sí, desde que llegamos, casi.. O sea que no fuimos de los primeros de la calle, pero, éramos menos familias. Éramos menos. Y entonces, más bien hicimos más sólido con las que llegamos... casi primero, no? Entonces de los de la entrada, de acá... Entonces sí hay más confianza de llegar y decirle: oye... (...) y luego nos habla: vénganse por acá a tomar café, o a desayunar (...) Pues sí nos ayudamos aquí, nos echamos la mano, verdad?»

El tema de la necesidad económica en las relaciones de vecinas es muy rápidamente tratado entre vecinas, y el interés hacia el contra-don queda muy claro, a veces está directamente enunciado: «tenemos que apoyarnos, no hay de otra, estamos solas 
(...) ahora te ayudo, tú me apoyas mañana». Cuanto más extrema sea la situación, o más reciente la instalación (en el caso del conjunto urbano el más nuevo: Santa Teresa) más asumido es el tratar abiertamente de esta problemática. Las vecinas tocan el tema a poco tiempo de conocerse, en el sentido del acreedor como del deudor, empezando con servicios leves tales como el regalo de un alimento, el cuidado de un niño por un corto momento, y acabando por el intercambio de bienes mayores, materiales, hasta de dinero. La calidad y durabilidad de los lazos de solidaridad son cuestión de etapas en el vecindario, puesto que, en un principio, la total precariedad apresura el desarrollo de amistades tan rápidas como frágiles. Estas relaciones de simpatía y solidaridad forman un primer ciclo de selección. Corresponden a una especie de «inversiones de riesgo», que van cambiando con el tiempo y la profundidad de las relaciones hacia opciones más fiables y estables, de tal modo que se va constituyendo una reserva de deudoras con potencial de préstamo, con periodicidades y para valores variados. Se accede así a un fondo seguro que otorga la capacidad de «estirar» el ingreso.

A mediano plazo este sistema económico colectivo funciona relativamente bien. La homogeneidad socioeconómica de las diferentes partes, así como una cierta asunción que permite transparencia, facilitan una autoregulación que protege de la posibilidad de caer en deudas elevadas y persistentes. El mayor factor de regulación queda el temor de dejar una reputación negativa y duradera en el vecindario, lo cual tendría como efecto la privación de todo apoyo de parte de la comunidad de vecinos. Por otro lado, siendo todos recién propietarios y teniendo todos la misma necesidad de ampliar y mejorar su casa, los apoyos, o ayuda al ahorro con esta finalidad principal, son socialmente valorados.

Después de «inversiones» de leve y mediano impacto, se encuentran entonces las «tandas». La tanda es un sistema informal de crédito rotativo organizado por los mismo pobladores en el que no se contempla el pago de ningún tipo de interés, y que se ajusta a las necesidades de los propios organizadores en primer lugar. Se trata por otro lado de una institución que contribuye a consolidar la relación entre los miembros que la componen en el marco de un sistema de ayuda mutua más amplio (Herrero Díaz, 1993: 15). Las tandas a su vez revelan las ramificaciones de las redes, pues responder positivamente a la llamada a una tanda es una forma de demostrar su solidaridad a los vecinos con una necesidad urgente de dinero y, por parte del organizador, de manifestar o corroborar la confianza que tiene con cada participante. La intensidad y constancia de los intercambios de dinero bajo formas múltiples, hacen de la cuestión monetaria un asunto omnipresente en el cotidiano de las mujeres, diseñando una frontera muy tenue entre transacción, intercambio y registro personal. En el conjunto residencial más reciente (Santa Teresa), el sistema de las tandas es muy claramente usado como instrumento para la creación de una red de confianza, en el cual se han empeñado mujeres que beneficiaban de una posición de liderazgo comunitario naciente. En un sistema de reciprocidad más maduro, la tanda puede reforzar lazos que ya hicieron sus pruebas, y llevar el grupo de personas involucradas hacia un desarrollo individual mayor, puesto que coincide frecuentemente con una motivación mutua entre vecinas para la 
creación de actividades económicas complementarias de tipo comercial o de servicio. Así, este modo de ahorro participativo ayuda a ritualizar una relación de solidaridad, dándole un aspecto menos moral y más emprendedor. Asimismo, se pone a prueba públicamente la capacidad de administración, autoridad y fiabilidad intrínseca a la responsable de una tanda exitosa.

Regularmente se observa una coincidencia entre organizadoras de tandas y líderes en varios ámbitos comunitarios tales como actividades sociales, educativas o recreativas en el conjunto residencial, un papel fuerte en los grupos de padres de alumnos, participación activas en los asuntos vecinales, o simplemente como mediadora en conflictos interpersonales, etc. Se les otorga además un lugar preferente en asuntos que implican un manejo de dinero colectivo. También se vuelven interlocutores evidentes en las gestiones realizadas con la empresa constructora y el gobierno municipal alrededor de las fallas en los servicios e infraestructuras, así como en la organización de los servicios sociales.

\section{COMPETENCIAS ESPACIALES: HACIA UN ESPACIO PÚBLICO FEMENINO}

El conjunto de las actividades a carácter económico, social y colectivo produce una interdependencia del grupo de vecinos dentro de, y entre calles cerradas, y libera en cierta medida a las mujeres de una existencia centrada en el hogar. En otras palabras las condiciones propias a la independencia reciente del hogar, así como la accesión a la propiedad y la instalación en un espacio residencial caracterizado por su aislamiento, tienden a desplazar el peso del ámbito privado hacia et ámbito público, en una segunda etapa de adaptación de los pioneros. Como se ha observado en la historia, las situaciones de crisis son favorables a cierto «empoderamiento» de las mujeres.

La diversidad de temperamentos dibuja perfiles distintos. Algunas mujeres se han desarrollado individualmente y han adquirido un papel más fuerte en su hogar y alcanzado un margen de independencia mayor que se expresa en las dimensiones del consumo personal, de gestión del tiempo, de la movilidad y por ende de la urbanidad, traspasando de tal modo la acumulación de límites físicos y funcionales propios a estas periferias.

El ejemplo de Carmen, residente de Santa Teresa, es elocuente. Una vez financiado el transporte cotidiano del esposo y la hipoteca, sus finanzas no les alcanza para financiar la alimentación del hogar. Con las monedas que pudiera ahorrar, y más adelante con tandas de montos reducidos, inició un comercio de accesorios femeninos «en una caja de zapatos» y por encargos, a la ventana de su vivienda y en el espacio público de su calle privada. Rápidamente se relacionó con vecinas con la misma actividad, las cuales además de motivarse entre sí, se apoyaban materialmente. Favorecida por la ausencia de comercios de proximidad en un principio, su capital fue aumentando muy paulatinamente y parte de la planta baja de su vivienda es ahora acomodada para su actividad. El capital 
administrado «justo a tiempo», le permite financiar un viaje encadenado al DF en transporte público. En un primer tramo realiza una escala en el centro histórico donde se da un tiempo de paseo antes de adquirir mercancía en mayoreo; toma nuevamente el transporte para llegar con su familia en el sur de la ciudad (esta cadena autofinanciada es la única manera para ella de realizar estas visitas) con quien realiza ventas por encargo con sus productos adquiridos en el centro. En esta etapa, además de un momento de sociabilidad, recobra una parte de su capital de inicio que le permite aprovisionarse nuevamente y financiar el transporte de regreso: hace entonces una segunda escala en el centro de la ciudad para una nueva inversión, y de allí regresa a Santa Teresa con su mercancía. En un círculo virtuoso, sus ventas hacen posibles una movilidad placentera en la metrópoli, que es a su vez vector de desarrollo de su comercio itinerante. Reconoce ella que la necesidad económica y la soledad fueron los factores de impulso hacia el desarrollo de una actividad, y que es fuente de satisfacción en todos los aspectos. A su vez este desarrollo material y personal transforma su papel de género al hacer de ella un sostén imprescindible para su hogar. Desde luego, el ingreso final es limitado, sin embargo el beneficio en el proceso es notorio debido a que hace posible un consumo y una movilidad orientados hacia el ocio, la sociabilidad y el vinculo familiar. El caso de Carmen es ilustrativo de experiencias similares con objetivos y habilidades variables. Algunas mujeres logran una independencia económica completa y el cambio de jefatura del hogar en tiempos cortos.

En la escala del vecindario, rebasando una representación de sí mismas limitada a las actividades del hogar, las residentes comprueban cierta libertad para llevar a cabo actividades sociales. Las dimensiones muy reducidas de las viviendas favorecen un desbordamiento de la convivencia a carácter vecinal sobre el espacio público. La presión inherente a un papel de género endurecido en un inicio puede en su momento impulsar las mujeres en buscar espacios de existencia en la esfera pública. Los problemas que emergen para los pioneros presentan pretextos de movilización para los intereses individuales y comunitarios, donde surgen personas con carisma notorio. Los campos más observados de organización son las mesas directivas de las escuelas para el control de la actividad educativa y financiera de las escuelas, la coordinación de proyectos colectivos con asociaciones y ONG que se presentan (proyectos educativos, culturales, ambientales, de acción sobre el espacio público, etc.), la coordinación de la demanda de ayuda social en mediación con el ayuntamiento y otras instituciones estatales descentralizadas (campañas de salud y educación, trámite de las becas escolares), la movilización para el beneficio de materiales de mantenimiento de las escuelas $u$ otro tipo de ayuda en especie por medios externos (iglesia, partidos políticos, etc.).

Pero los objetos mayores de desarrollo de liderazgo han sido las luchas frente al municipio y a la empresa constructora para obtener el cumplimiento de los servicios prometidos. Asimismo, las fallas o la ausencia de los servicios básicos administrados por la empresa desarrolladora antes de la entrega de obras (suministro de agua, luz, recolección de basura, seguridad pública) son frecuentes en los primeros meses de instalación. De tal modo, las movilizaciones fueron 
tan necesarias como recurrentes, y rápidamente hicieron que se distinguieran personas con habilidades de negociación. En un principio no estructurados se generaron agrupamientos que no corresponden de forma estricta con las calles cerradas, en base a las afinidades interpersonales previas y consecutivas. Las quejas y «plantones» espontáneos frente a las oficinas comerciales de la empresa (siempre situadas en los conjuntos residenciales), a los edificios del ayuntamiento, o en las bases de transporte urbano, se han prolongado en todos los casos hasta obtener resultado.

Por otro lado, no se han dado formas de organización oficiales de tipo asociativa, tal como lo plantea sin embargo el régimen de condominio que rige en teoría las calles cerradas de los conjuntos residenciales. Se supone que el diseño de estos conjuntos residenciales, en «peine» y calles privadas, propicia una organización social ordenada bajo esta estructura espacial, pero la organización de los habitantes ha aparecido bajo otras lógicas, independientemente de los enclaves del espacio interno. Se puede suponer que el contexto socioeconómico presente, junto con la situación urbana de estos espacios, privilegian mecanismos de organización bajo una lógica de utilitarismo y hacia la resolución de las necesidades básicas. Así, no se ha enfocado hacia otras problemáticas que la de los servicios más importantes (suministro de luz, agua, obras viales más importantes, seguridad en fases ulteriores). En reacción a la falta de apoyo municipal, la infracción sistemática de otras normas de administración de los conjuntos residenciales es consensual en la comunidad de los residentes, siempre y cuando permite usos necesarios para la comunidad, como por ejemplo una movilidad interna más fluida en el interior y con el exterior del conjunto, o el desarrollo de un comercio informal. Aunque deplorada por la mayoría, estas inconformidades no sorprenden los residentes y es de cierta forma asumida. Pero el hecho central es que la movilización ha propiciado la emergencia de liderazgos comunitarios sólidos y replicables en cualquier ámbito. Esta emulación ha ampliado a su vez el universo de existencia de los residentes, en particular las mujeres, hacia territorialidades más extensas y hacia esferas diversas como la mediación entre la comunidad y los poderes públicos.

\section{A MODO DE CONCLUSIÓN}

Al cristalizar condiciones de crisis en las trayectorias de los individuos y de los hogares así como en los territorios municipales que los acogen, los conjuntos residenciales recientes de bajo costo constituyen laboratorios elocuentes sobre los modos y procesos de organización social. A la luz de una trayectoria plurigeneracional, los pioneros se movilizan en varias escalas del hogar a la colectividad con el propósito de cubrir sus necesidades y consolidar su núcleo residencial. En paralelo, se organizan para hacer frente a los problemas encontrados en busca de una mejora general del espacio, bajo competencias tan espontáneas como eficaces. A tenor de una dimensión temporal, se observan dinámicas distintas en espacios más consolidados. La mayor cohesión de una comunidad madura podría resultar evidente, después de haber compartido una fase de reivindicaciones. Sin 
embargo la etapa inicial que logra en su momento federar los intereses hacia la construcción de un lugar de vida digno, cede el paso a una situación estable donde se tiende a evitar todo tipo de asunto colectivo. Asimismo, a lo largo de la década en los conjuntos residenciales observados, las redes sociales desarrolladas persisten pero bajo una forma más estable, afín y restringida. Entran en juego la estabilización económica de las familias y la comodidad relativa alcanzada en los conjuntos. Una movilidad más frecuente con motivo de visita a sus familiares se restablece $y$, por lo tanto, reequilibra las relaciones sociales entre un afuera y un adentro, y modera la dependencia hacia las solidaridades cotidianas y locales.

A pesar de definirse en apariencias con contornos más rígidos que antes en sus trayectorias familiares, los papeles de género proyectan nuevos dominios. Si bien los hombres están globalmente ausentes del espacio del conjunto, las mujeres permanecen en cambio al centro de los asuntos públicos locales. Desarrollan y acceden a nuevas competencias y prácticas sociales y espaciales, las cuales permiten abrir nuevas geografías personales frente a lo que sugiere un espacio definido por la discontinuidad en todas sus escalas.

La capacidad de las capas populares para «adaptarse» y enfrentar activamente sus problemas es sin embargo pretexto a cierta pasividad de los gobiernos en materia de planeación integral de la ciudad. Al no producir crisis contundas, se siguen delegando los problemas urbanos a todos los actores ubicados en el final de la cadena: en cierto modo a las empresas inmobiliarias, a los gobiernos locales, pero sobre todo a los habitantes. La experiencia de los grupos populares del contacto con lo político produce a menudo en ellos una interpretación oportunista y sin ilusión de la administración pública, bajo el registro general de la oposición para lograr obtener beneficios, a falta del respeto de sus derechos. En cambio los gobiernos locales, con grandes dificultades presupuestales, suelen alentar la representación organizada de los habitantes. Esta mediación constituye un recurso humano informal y gratuito que también permite ahorrarse una reflexión sobre cómo conducir programas integrales hacia estas poblaciones específicas, las cuales, se subraya, no son las más necesitadas. Los habitantes se movilizan para sus demandas más importantes, y se ejerce como antes en otros contextos una política del parche.

\section{Referencias citadas}

ADLER DE LOMNITZ, L., 1993 - Cómo sobreviven los marginados, 229 pp.; México: D.F.: Siglo XXI.

BERRY-CHIKHAOUI, I. \& DEBOULET, A., 2000 - La compétence des citadins dans le Monde arabe. Penser, faire, et transformer la ville, 406 pp.; París: Karthala, coll. « Hommes et sociétés ».

CARTIER, M., COUTANT, I., MASCLET, O. \& SIBLOT, Y., 2008 - La France des "petitsmoyens": enquête sur la banlieue pavillonnaire, 324 pp.; París: Ed. La Découverte. 
CHOMBART DE LAUWE, P.-H., JENNY, J., COUVREUR, L., LABAT, P., RETEL, J., CHARAZAC, J., CHOMBART DE LAUWE, M.-J., ROCHER, G., DUBOIS-TAINE, D. \& PERROY, E., 1960 - Famille et habitation, Tome II: Un essai d'observation experimentale, 364 pp.; París: Centre National de la Recherche Scientifique.

DE CERTEAU, M., 1996 - La invención de lo cotidiano. T.1: Artes de hacer, 229 pp.; México, D.F.: Universidad Iberoamericana, ITESO, CEMCA.

DUHAU, E. \& JACQUIN, C., 2008 - Les ensembles de logement géants de Mexico. Nouvelles formes de l'habitat social, cadres de vie et reformulations par les habitants. Autrepart, 47: 169-186.

FOSTER, G. M., 1953 - Cofradía and Compadrazgo in Spain and Spanish America. Southwestern Journal of Anthropology, 9 (1): 1-28.

GUTMANN, M. C., 2006 - The meanings of macho: being a man in Mexico City, 364 pp.; Berkeley and Los Angeles, California: University of California Press.

HERRERO DÍAZ, L.F., 1993 - Desarrollo urbano y estrategias de supervivencia en la periferia de la ciudad de México: Chalco, una aproximación antropológica. Revista española de antropología americana, 23: 213-232.

HIERNAUX, D. \& LINDON, A., 2003 - Pratiques et stratégies résidentielles dans la vallée de Chalco, périphérie de Mexico. Autrepart, 25: 123-136.

INSTITUTO NACIONAL DE ESTADÍSTICA, GEOGRAFÍA E INFORMÁTICA, 2007 Encuesta Origen-Destino; México.

INSTITUTO NACIONAL DE ESTADÍSTICA, GEOGRAFÍA E INFORMÁTICA, 2000 - Censo general de población y vivienda; México.

INSTITUTO NACIONAL DE ESTADÍSTICA, GEOGRAFÍA E INFORMÁTICA, 2010 - Censo general de población y vivienda; México.

MAYA, E. \& CERVANTES BORJA, J., 2005 - La producción de conjuntos habitacionales en el Estado de México; El caso del Municipio de Ixtapaluca. In: RNIU: 218 pp.; Puebla: Red Nacional de Investigación Urbana.

MONNET, J., 2010 - El territorio reticular. Anthropos «Nuevos territorios e innovación digital», 227: 91-104.

OAKLEY, A., 1974 - Housewife, 225 pp.; New York: Penguin.

SINGLY (de), F., 2002 - Fortune et infortune de la femme mariée : sociologie des effets de la vie conjugale, 225 pp.; París: Presses Universitaires de France.

TAMAYO, S. (ed.), 2007 - Los desafíos del Bando 2. Evaluación multidimensional de las políticas habitacionales en el Distrito Federal 2000-2006, 293 pp.; México, D.F.: Secretaria de Desarrollo Urbano y de Vivienda.

YOUNG, M. \& WILLMOTT, P., 1983 - Le village dans la ville, 255 pp.; París: Centre Georges Pompidou, Centre de la Création Industrielle. 